\title{
Quantitative tear lysozyme assay in units of activity per microlitre
}

\author{
I. A. MACKIE AND D. V. SEAL \\ From St George's Hospital and Public Health Laboratory, and Moorfields Eye Hospital, London
}

Fleming (1922) discovered lysozyme, and in 1932 he assayed the tear level using a dilution technique (Fleming, 1932). He showed that the concentration of lysozyme in tears was up to a thousandfold greater than in serum.

Accurate lysozyme assay has been possible only since the establishment of hen egg lysozyme (HEL) and human lysozyme (HL) standards. Their activity can be accurately measured. HEL standards have recently been used for lysozyme assay in urine, peritoneal fluid, and serum and HL standards have been used for assay in cerebrospinal fluid (Parry, Chandian, and Shahani, I965; Harrison, Lunt, Scott, and Blainey, I968; Wardle, 1973; Cacatian, Newman, Josephson, and Tsang, 1974).

Tear fluid is most easily collected by filter paper disc absorption. Results of the total quantity of lysozyme on the discs, have been expressed in diameters of zones of lysis of Micrococcus lysodeikticus. Various authors have reported different normal diameters (Bonavida and Sapse, 1968; Bijsterveld, I969; el Gammel and Salah, 1971; Pietsch, Pearlman, and Durham, 1973; Bijsterveld 1974). Results have also been expressed in $\mu \mathrm{g} / \mu \mathrm{l}$ of uncalibrated HL (Pietsch and others, 1973), of HEL (Covey, Perillie, and Finch, 197I), and calibrated HEL (Osserman and Lawlor, 1966; Friedland, Anderson, and Forster, 1972). Direct comparison of these results is unreliable, because HEL and HL vary in their activity per $\mu \mathrm{g}$, as shown by the different levels quoted (Harrison and others, I968; Bonavida and Sapse, I968; Friedland and others, 1972; Bijsterveld, 1974). In addition, batches of lysozyme standards are prepared by different commercial laboratories; further confusion arises because HL has eight to 12 times the activity of HEL per $\mu \mathrm{g}$ (Osserman and Lawlor, I966).

In this study, calibrated HEL standards were used in each assay alongside the test discs. The activity of this HEL standard was measured in 'units of activity' per $\mu \mathrm{g}$, so that direct comparison

Address for reprints: I. A. Mackie, Moorfields Eye Hospital, City Road, London ECIV 2PD with other results, in units, could be made. $t$ 'unit of activity' is defined below.

\section{Method}

Dried, autoclaved Whatman No. I filter paper discs $\rightarrow$ $6 \mathrm{~mm}$ in diameter, were placed inside bijoux bottle $c$ which were weighed and put into clear plastic envelopes The disc was placed in the lower fornix of the conjunc tiva with a forceps, allowed to absorb tear fluid, an $₹$ then replaced in the bottle. Care was taken to avoir $\vec{\theta}$ collecting the mucus thread in the lower fornix. Th o bijou bottle, with the wet disc, was reweighed so tha the volume of tear fluid could be calculated. Other disc were wetted with standard HEL at a concentration o I, 3, 5, and Io $\mu \mathrm{g} / \mu \mathrm{l}$ and the volume absorbed was agaii estimated by weighing. A control disc of HEL wa similarly treated.

Twenty colonies of $M$. lysodeikticus, from a purit $\stackrel{\varrho}{\Rightarrow}$ plate, were innoculated into $20 \mathrm{ml}$ nutrient broti (Oxoid), and shaken for $2 \mathrm{~min}$. This was flooded on to $20 \mathrm{~cm}^{2}$ plate, containing $250 \mathrm{ml}$ Direct Sensitivity Tes Agar (DST-1 2 per cent Oxoid), and dried (Bijsterveld 1974). The discs for the tests, standards, and control 0 were placed on the surface of the plate, which wa incubated at a temperature of $37^{\circ} \mathrm{C}$ for $18 \mathrm{~h}$. Zones o lysis of the $M$. lysodeikticus occurred around the discs The diameters of these zones were measured witl precision calipers.

The HEL standard was calibrated in a spectrophoto 은 meter by measuring the rate of lysis of a fresh substrat $D$ of $M$. lysodeikticus grown for $48 \mathrm{~h}$ on Meyer and Hahnt medium (Meyer and Hahnel, 1946; Shugar, 1952). Th $M$. lysodeikticus was suspended in $\mathrm{M} / \mathrm{1} 0$ phosphat or buffer at $\mathrm{pH} 7 \cdot 0$. The absorption of the suspension in $\mathrm{N}$ $3 \mathrm{ml}$ spectrophotometer cuvette was adjusted to be N tween 0.5 and 0.6 with a wavelength of $450 \mathrm{~nm}$ at $\omega$ temperature of $25^{\circ} \mathrm{C}$. Samples of $10,20,30$, and $40 \mu$ of the $\mathrm{I}, 3,5$, and 1o $\mu \mathrm{g} / \mu \mathrm{l} \mathrm{HEL}$ standards, each dilute to $0.3 \mu \mathrm{g} / \mu \mathrm{l}$, were added to the cuvette so that th $\overparen{D}$ concentration of the HEL was known in $\mu \mathrm{g} / \mathrm{ml}$ buffe $\stackrel{\oplus}{?}$ substrate. The decrease in absorption during the firs $\underline{T}$ minute was measured.

One 'unit of activity' was defined as that amount c $\stackrel{\mathbb{D}}{\mathbb{D}}$ enzyme required to cause a decrease in absorption c $\overrightarrow{\mathbb{D}}$ the $M$. lysodeikticus substrate, in $\mathrm{M} / \mathrm{ro}$ phosphat kuffer at $\mathrm{pH} 7.0$ and at a temperature $25^{\circ} \mathrm{C}$, of 0.001 in th first minute of the reaction, at a wavelength of $450 \mathrm{~nm}$ ?

The HEL standards had to be kept deep froze $\left(-20^{\circ} \mathrm{C}\right)$ as they would have lost some of their activit 
at temperatures above $4^{\circ} \mathrm{C}$. The standards used for the plate assay were checked monthly on the spectrophotometer, against the calibration curve, to assess whether they had lost any activity.

\section{Results}

A straight line graph was obtained between the logarithms of the total quantities of the HEL in $\mu \mathrm{g}$ on the discs and the squares of the diameters of the zones of lysis of $M$. lysodeikticus on the plate, in the range equivalent to that in human tears (Fig. I); a non-lysozyme antibacterial factor has been described in human tears (Friedland and others, 1972). It has been neither identified nor assayed, and it has not been taken into account in this method.

A straight line graph was obtained with the HEL calibration on the spectrophotometer (Fig. 2) (Parry and others, 1965). A decrease in absorption during the first minute of 0.030 was obtained by I $\mu \mathrm{g} \mathrm{HEL} / \mathrm{ml}$ buffer-substrate, under stated conditions. This represented, by our definition, 30 'units of activity'/ $\mu \mathrm{g}$ HEL (30 000 units/mg).

It was necessary for the standard HEL, which was used in the test, to be calibrated in the laboratory. Lysozyme chloride ex egg white* was stated to have an activity of approximately 15000 units/ mg. On repeated testing of freshly prepared solutions, however, an activity of 30000 units $/ \mathrm{mg}$ iwas recorded.

The lysozyme concentration in units of activity/ $\mu$ l tear fluid, of the normal eyes of 54 volunteers (aged 18 to 86 years) was assayed (Fig. 3). The

*Supplied by Koch-Light Laboratories

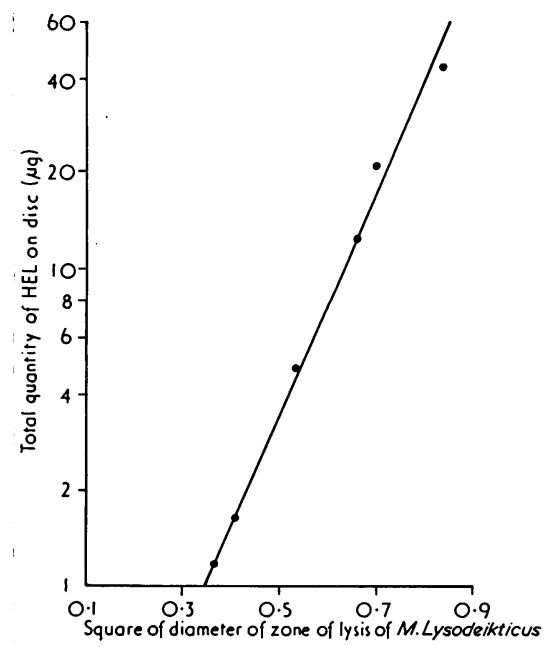

FIG. I Calibration graph of HEL on plate of $\mathrm{M}$. lysodeikticus

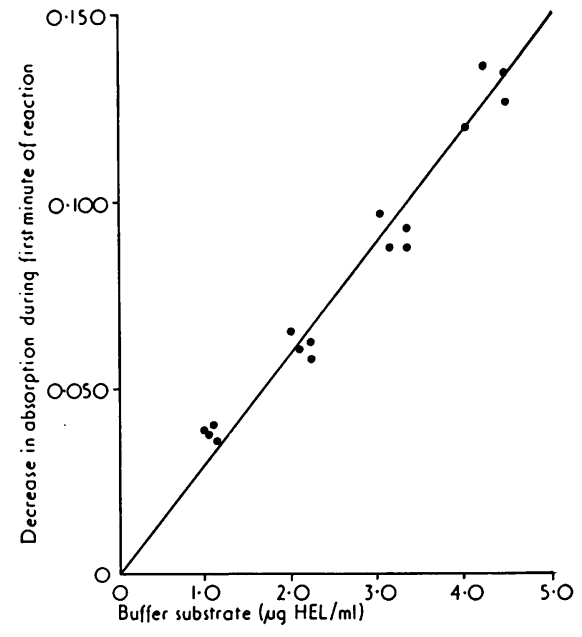

FIG. 2 Calibration graph of HEL on spectrophotometer

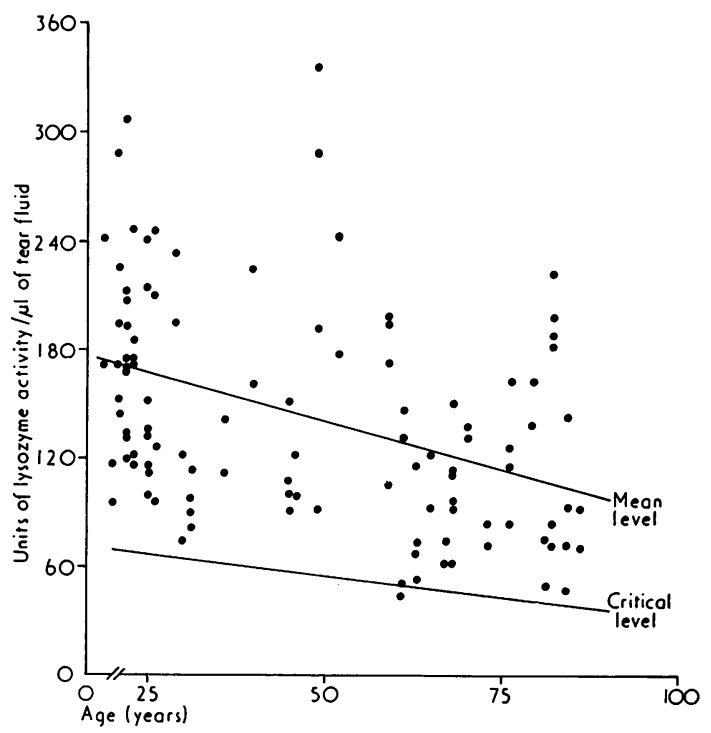

FIG. 3 Lysozyme concentration by age in 54 normal subjects

mean level of this distribution decreased by one unit of activity $/ \mu 1$ tear fluid for each year. A limit of 70 units of activity/ $\mu 1$ tear fluid at 20 years of age had decreased to 40 units $/ \mu 1$ tear fluid by 85 years, and this was considered to represent the lowest normal concentration, although one in 108 eyes lay below it; it is called the critical limit.

The variability of the volume of tear fluid absorbed by the Whatman filter paper discs, which were considered 'wet' on inspection, is shown in Table $\mathrm{I}$. In all age groups, the volume collected on a 'wet' disc could vary by threefold, and between 
Table I Volume of tear fluid absorbed on to filter paper discs from 54 normal volunteers

\begin{tabular}{|c|c|c|c|c|}
\hline $\begin{array}{l}\text { Age- } \\
\text { group } \\
\text { (years) }\end{array}$ & $\begin{array}{l}\text { No. } \\
\text { per } \\
\text { group }\end{array}$ & $\begin{array}{l}\text { Range of } \\
\text { volume } \\
(\mu l)\end{array}$ & $\begin{array}{l}\text { Mean } \\
(\mu l)\end{array}$ & $\begin{array}{l}\text { Standard } \\
\text { deviation }\end{array}$ \\
\hline $20-39$ & 24 & $2 \cdot 0$ to 8.5 & $5 \cdot I$ & $I \cdot 5$ \\
\hline $40-59$ & 9 & 2.3 to 6.5 & 4.5 & $I \cdot 2$ \\
\hline $60-89$ & 21 & $2 \cdot 2$ to $6 \cdot 5$ & $4 \cdot 3$ & $I \cdot 2$ \\
\hline
\end{tabular}

the ages of 20 and 40 years, by fourfold. The mean volume collected varied from $5 \cdot \mathrm{I} \mu \mathrm{l}$ for 20 to 39 years of age to $4.3 \mu \mathrm{l}$ for 60 to 89 years.

Out of 54 normal volunteers, four were slow in their response to produce enough tear fluid to wet the disc, and II were quick, producing copious quantities of tears, see Fig. 4 . The other volunteers were classified as 'medium tear producers'. It was demonstrated that tear fluid produced slowly could have a high or low normal lysozyme concentration, as was also the case for tear fluid produced quickly and copiously.

There was no relationship between the lysozyme concentration, measured in units of activity $/ \mu l$ tear fluid, and the total quantity of tear fluid absorbed by the disc (correlation coefficients: $-0 \cdot \mathrm{I}$ for left eye, -0.1 for right eye) (Fig. 5). This meant that volunteers producing smaller quantities of tear fluid ( 2 to $3 \mu$ absorbed by the disc) might have a high or low normal lysozyme concentration. This was also the case for volunteers producing larger quantities of tear fluid (6 to $7 \mu$ l absorbed by the disc).

A significant association between the lysozyme concentration in the left and right eyes of the volunteers was calculated (correlation coefficient: $0.7)$.

The details of six patients with a clinical diag-

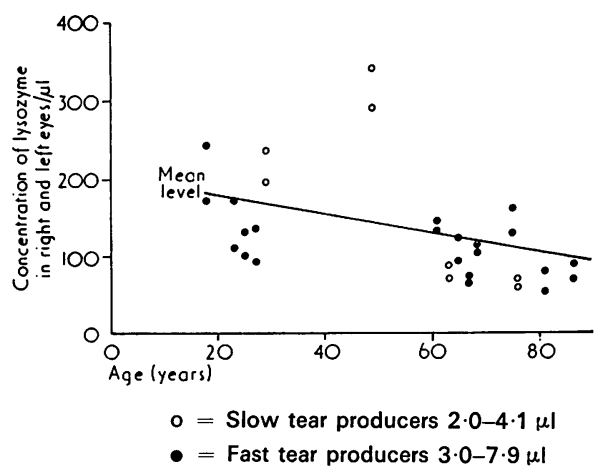

FIG. 4 Comparison of lysozyme concentrations in slow and fast tear producers

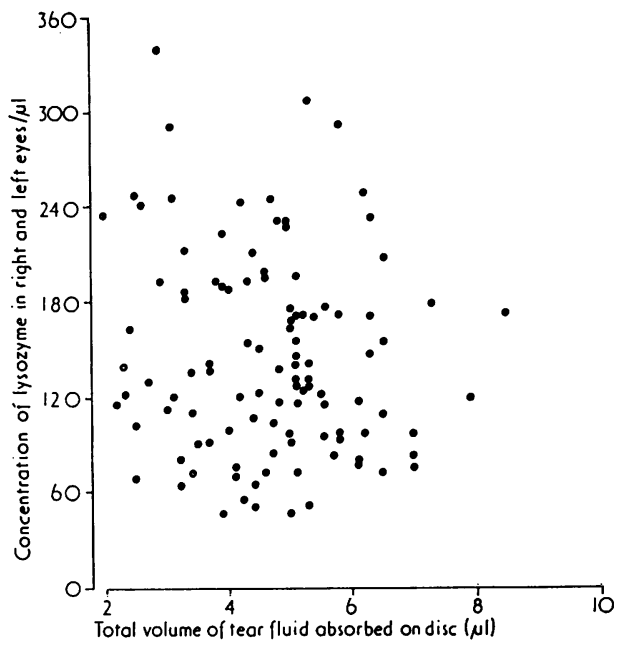

FIG. 5 Total volume of tear fluid absorbed by disc compared with lysozyme concentration

nosis of keratoconjunctivitis sicca, and three control patients with severe autoimmune disease, but with normal eyes, are summarized in Table II. Five out of the six patients with keratoconjunctivitis sicca had tear lysozyme concentrations wello below the critical limit for the lowest normal con- $\frac{\mathcal{Q}}{\varnothing}$

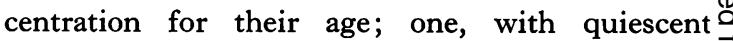
systemic lupus erythematosus and keratoconjunc- $\vec{\partial}$ tivitis sicca, had a lysozyme concentration around the limit. The three control patients had lysozyme concentrations well above the critical limit.

\section{Discussion}

Bonavida and Sapse (1968) stated that the variables affecting the diameter of the zone of lysis of the $M$. lysodeikticus include incubation time, tempera. ture, concentration of micrococcus, and thickness of agar. Bijsterveld (1974) investigated differen media for growing the $M$. lysodeikticus in order $\mathrm{t}(\mathrm{O}$ find a medium on which to standardize the test $\mathrm{N}$ Pietsch and others (1973) stated that the reporting $N$ of results, compared with a lysozyme standard N was not necessary because the zone of lysis ob. tained with a standard might be erroneous becauss of impurities.

In our experience the growth of the $M$. lyso. deikticus on DST agar ( $\mathrm{r} \cdot 2$ per cent Oxoid) is neve ${ }^{-}$ exactly the same, and direct comparison betweer 0 zones of lysis is unreliable. It is only by direc $\mathbb{D}$ comparison with a reliable standard on each plat $\frac{?}{\mathbb{D}}$ that the biological variable (that is the growth o: the M. lysodeikticus) can be compensated. If the lysozyme standard is calibrated on the spectro. photometer into units of activity, compensatior can be made for impurities and different strengths 
Table II Clinical details of six patients and three controls

\begin{tabular}{|c|c|c|c|c|c|c|}
\hline & \multirow{2}{*}{$\begin{array}{l}\text { Age of } \\
\text { patient } \\
\text { (years) }\end{array}$} & \multirow{2}{*}{ Diagnosis } & \multicolumn{2}{|c|}{$\begin{array}{l}\text { Volume of tear } \\
\text { fluid }\end{array}$} & \multirow{2}{*}{$\begin{array}{l}\text { Lysozyme } \\
\text { concentration } \\
\text { (units } / \mu l)\end{array}$} & \multirow{2}{*}{$\begin{array}{l}\text { Critical } \\
\text { limit* } \\
\text { (units } / \mu l)\end{array}$} \\
\hline & & & Eye & $(\mu l)$ & & \\
\hline \multirow[t]{11}{*}{ Sicca syndrome } & 23 & $\begin{array}{l}\text { Hypergammaglobulinaemia } \\
\text { with sicca }\end{array}$ & $\begin{array}{l}\text { Right } \\
\text { Left }\end{array}$ & $\begin{array}{l}2 \cdot 5 \\
2 \cdot 4\end{array}$ & $\begin{array}{l}39 \\
39\end{array}$ & 69 \\
\hline & \multirow[t]{2}{*}{33} & \multirow{2}{*}{$\begin{array}{l}\text { Quiescent systemic lupus } \\
\text { erythematosus and sicca }\end{array}$} & Right & $4 \cdot 0$ & 60 & \multirow[t]{2}{*}{65} \\
\hline & & & Left & $2 \cdot 5$ & 71 & \\
\hline & \multirow[t]{2}{*}{52} & \multirow[t]{2}{*}{ Sicca } & Right & $6 \cdot 2$ & I 5 & \multirow[t]{2}{*}{$5^{6}$} \\
\hline & & & Left & $4 \cdot 8$ & 15 & \\
\hline & \multirow[t]{2}{*}{60} & \multirow[t]{2}{*}{ Sicca } & Right & $5 \cdot 6$ & 24 & \multirow[t]{2}{*}{52} \\
\hline & & & Left & 4.2 & 30 & \\
\hline & \multirow[t]{2}{*}{66} & \multirow[t]{2}{*}{ Sicca } & Right & $2 \cdot 9$ & $<9$ & \multirow[t]{2}{*}{49} \\
\hline & & & Left & $2 \cdot 4$ & $<9$ & \\
\hline & \multirow[t]{2}{*}{82} & \multirow[t]{2}{*}{ Sicca } & Right & $3 \cdot 6$ & I9 & \multirow[t]{2}{*}{$4 \mathrm{I}$} \\
\hline & & & Left & $\mathrm{I} \cdot 8$ & 44 & \\
\hline \multirow{10}{*}{$\begin{array}{l}\text { Controls with other } \\
\text { autoimmune diseases }\end{array}$} & \multirow[t]{2}{*}{54} & \multirow{2}{*}{$\begin{array}{l}\text { Severe rheumatoid arthritis } \\
\text { Normal tear film and eyes }\end{array}$} & Right & $2 \cdot 9$ & 87 & \multirow[t]{2}{*}{55} \\
\hline & & & Left & $2 \cdot 4$ & 72 & \\
\hline & \multirow[t]{3}{*}{55} & Raynaud's disease & Right & $2 \cdot 8$ & 84 & \multirow[t]{5}{*}{54} \\
\hline & & Scleroderma & Left & $4 \cdot 0$ & 120 & \\
\hline & & Skin biopsy positive for & & & & \\
\hline & & $\begin{array}{l}\text { systemic lupus } \\
\text { erythematosus }\end{array}$ & & & & \\
\hline & \multirow{4}{*}{67} & Normal tear film and eyes & & & & \\
\hline & & Sjögren's syndrome (dry & Right & $2 \cdot 7$ & 64 & \multirow[t]{3}{*}{48} \\
\hline & & $\begin{array}{l}\text { mouth and rheumatoid } \\
\text { arthritis) }\end{array}$ & Left & $2 \cdot 2$ & 78 & \\
\hline & & Normal tear film and eyes & & & & \\
\hline
\end{tabular}

* Lowest normal level for age

It is essential to weigh the filter paper discs to estimate the quantity of tear fluid absorbed. Otherwise, the diameter of the zone of lysis of the $M$. lysodeikticus will be increased by 40 per cent for each doubling of the quantity of tear fluid on the disc.

Erickson (1955) and McEwen and Kimura (1955) reported the absence of lysozyme in the sicca syndrome, and Minton (1965) reported its absence in one case of systemic lupus erythematosus, with some reduction in other cases.

We have shown in this study that the tear lysozyme concentration is likely to be abnormal, if it lies below a critical limit, which varies with age.

Bijsterveld (1973) found that the probability of misclassification of a patient with keratoconjunctivitis sicca by Schirmer's test was I 5 per cent, by rose bengal test 5 per cent, and by his lysozyme method I per cent. Pinschmidt (1970) showed that Schirmer's test was inconsistent. We suggest that the tear lysozyme concentration, in units of activity $/ \mu 1$ tear fluid, provides the ophthalmologist with a good guide to lacrimal gland function.

\section{Summary}

An accurate method of assaying the tear lysozyme concentration in units of activity/ $\mu$ l has been developed. Normal physiological levels which vary with age have been determined.

It has been demonstrated that measurement of the volume of tear fluid collected and assay with a calibrated standard are essential for the accurate determination of the precise concentration of lysozyme in the tear fluid.

Tear lysozyme concentration can be used as an index of lacrimal gland function, and in the diagnosis of the sicca syndrome and associated conditions.

We believe that this method of tear lysozyme assay has important applications in drug toxicity states in humans (for example, practolol toxicity) and also in animal drug toxicity studies.

We wish to thank Dr H. Cleeve for advice on chemistry, Mrs A. Clewer for advice on statistics, and $\mathrm{Dr} D$. Fleck, Dr H. Ross, and Mr B. Chessum for advice on bacteriology. 


\section{References}

BIJSTERVELD, O. P. VAN (1969) Arch. Ophthal., 82, IO (1973) Ophthalmologica (Basel), 167, 429

(1974) Arch. Ophthal., 91, 432

BONAVIDA, B., and SAPSE, A. T. (1968) Amer. F. Ophthal., 66, 70

CaCATIAN, A., NEWMAN, J., JOSEPHSON, A. S., and TSANG, A. (1974) Lancet, 2, 756

COVEY, w., PERILlie, P., and FINCH, s. c. (1971) Proc. Soc. exp. Biol. (N.Y.), 137, 1362

EL GaMMEL, M. Y., and SALAH, M. (197I) Bull. ophthal. Soc. Egypt, 64, 285

ERICKSON, O. F. (1955) Stanf. med. Bull., 13, 292

FLEMING, A. (1922) Proc. roy. Soc. B, 93, 306

(1932) Proc. roy. Soc. Med., 26, $7 \mathrm{I}$

FRIEDLAND, B. R., ANDERSON, D. R., and FORSTER, R. K. (1972) Amer. F. Ophthal., 74, 52

HARRISON, J. F., LUNT, G. S., SCOTT, P., and BLAINEY, J. D. (1968) Lancet, I, 37 I

MCEWEN, W. K., and KIMURA, s. J. (1955) Amer. F. Ophthal., 39, 200

MEYER, K., and HAHNEL, E. (1946) F. biol. Chem., 163, 723

MinTon, L. R. (1965) Amer. F. Ophthal., 6o, 532

osserman, E. F., and LAWLOR, D. P. (1966) F. exp. Med., 124, 921

PARRY, R. M., Chandian, R. C., and ShahaNi, K. M. (1965) Proc. Soc. exp. Biol. (N.Y.), I19, 384

PIETSCH, R. L., PEARLMAN, M. E., and DURhaM, N. C. (1973) Arch. Ophthal., 90, 94

PINSCHMIDT, N. W. (1970) Sth. med. F., 63, 1256

SHUGAR, D. (1952) Biochim. biophys. Acta (Amst.), 8, 302

WARDLE, E. N. (1973) Brit. med. F., 2, 518 